\title{
Chemical compositions of the essential oils of inflorescence and vegetative aerial parts of Elsholtzia blanda (Benth.) Benth. (Lamiales: Lamiaceae) from Meghalaya, North-East India
}

\section{Rumi Kotoky*, Siddhartha Pratim Saikia, Bithika Chaliha and Subhan Chandra Nath}

Division of Biological Sciences and Technology (Medicinal, Aromatic and Economic Plants, Groups). CSIR - North East Institute of Science and Technology. Jorhat 785006. India.*Email: kotoky15@yahoo.co.in.

\begin{abstract}
The compositional analysis of essential oil content in inflorescence and vegetative aerial parts of Elsholtzia blanda Benth. (Lamiales: Lamiaceae) growing wild in Meghalaya,North-East India were studied by GC and GC-MS. A total of 30 and 17 components representing 96.9\%-98.3\% and 92.6\%-92.8\% of the total oils from the inflorescence and vegetative aerial parts, respectively, were identified. Significant difference in composition of oils were observed between the two plant parts; 15 components detected in the oil of inflorescence were lacking in the oil of vegetative aerial parts, while two components present in the oil of vegetative aerial parts were absent in the inflorescence oil. Linalool was the major component in oils of both inflorescence (77.3\%-80.2\%) and vegetative aerial parts (57.9\%-62.9\%). Trans- linalool oxide (8.4\%9.9\%), cis-linalool oxide (8.3\%-9.3\%) and 3,7-dimethyl-1,5octadiene-3,7-diol (4.7\%-5.1\%) were however found in higher amount in the oil of vegetative aerial parts compared to inflorescence. For the first time the composition of oil in the inflorescence part has been reported in this communication while the oil from vegetative aerial parts containing linalool as the major component (44.9\%) was although reported earlier but comparatively higher percentage of same was observed in vegetative aerial part (57.9\%-62.9\%) and inflorescence (77.3\%-80.2\%) in the present investigation with the plants from Meghalaya, India.
\end{abstract}

Keywords: Elsholtzia blanda; Lamiaceae; Essential oil composition; Linalool; Trans-linalool oxide; Cis-linalool oxide.
Received

January 23, 2017

Accepted

June 1, 2017

Released

June 30, 2017

Open Acess

Full Text Article

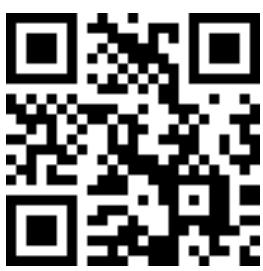

ORCIID

(1) 0000-0001-9709-2586 Rumi Kotoky

(1) 0000-0003-3696-8200 Siddhartha Pratim Saikia

다 0000-0001-9796-7506 Bithika Chaliha

(c) 0000-0002-7726-8991 Subhan Chandra Nath

\section{Introduction}

Elsholtzia blanda (Benth.) Benth. (Lamiales: Lamiaceae) is a perennial shrub distributed in China (Sichuan, Yuman, Guizhou and Guangxi Provinces), Bhutan,
India, Indonesia, Myanmar, Nepal, Thiland and Vietnam. It is in fact a Chinese traditional medicinal plant used for treating hepatitis, nephritis, dysentery, pharyngitis and acute enteritis (Lu et al., 2001). In India specially in its North-East part, E. blanda is 
reported in hilly areas up to an altitude of about $1,700 \mathrm{~m}$. with warm climatic condition and widely used as folk medicine for the treatments of cuts and wounds, cough, choleric diarrhoea, dysentery, dyspepsia, dizziness, fever, piles, skin disease including eruptions and sore throat etc.(Singh, et al. 2003; Nath, 2010; Devi, et al 2014; Singh, et al. 2014). Because of the presence of flavonoid luteolin, the plant is also reported to be useful in the treatments of cardiovascular disorders (Lazaro, 2009).

Almost all parts of the plant are aromatic and yield essential oil. However, compositional variations in the essential oils of the plant also have been reported indicating geranial acetate, 1,8-cineole, citral and linalool as major components (Fang et al. 1990; Bestman et al., 1992; Rana et al., 2012; Thapp et al., 1999). Moreover, significant variation in the essential oil content and its associated chemical componens with time and space depending upon the agro-climatic condition of different regions also reported (Cheng et al., 1989; Lesueur et al., 2007; Shen et al., 2001). Observing this an exploratory investigation has been attempted with the plants from Meghalaya, North-East India. The essential oil content of inflorescence and vegetative aerial parts of E. blanda have been studied and reported in this communication. However, the essential oil of the inflorescence part of this plant is reported for the first time.

\section{Materials and methods}

\section{Plant material}

The plant materials under study was collected at vegetative (September) and full blooming stage (December) of the plant from the foot hill areas of Nokrek Biosphere Reserve $(1,400 \mathrm{~m})$ of Meghalaya, India. Identity of the species was confirmed at the Herbarium of Botanical Survey of India (BSI) Shillong, Meghalaya, India, followed by the deposition of its voucher Specimen No. 1175 at the Herbarium of CSIR - North East Institute of Science \& Technology, Jorhat (Assam), India.

\section{Isolation of essential oil}

The fresh vegetative aerial parts and inflorescence of $E$. blanda were cut into small pieces and $300 \mathrm{~g}$ each of the plant parts were separately hydrodistilled using Clevenger type apparatus for $3 \mathrm{~h}$. The oils thus obtained (v/w basis) from vegetative and inflorescence parts were dried over anhydrous sodium sulphate and stored in refrigerator prior to analysis by GC and GC/MS.

\section{Gas chromatography/Mass spectroscopy \\ GC analysis of extracted oil were} carried out on a Perkin-Elmer 8500 gas chromatograph equipped with Flame Ionized Detector (FID) and a HP-1 fused silica column ( $24 \mathrm{~m} \times 0.32 \mathrm{~mm}, 0.17 \mu \mathrm{m}$ film thickness). The samples, dissolved in hexane, were injected in the split mode, using pressure controlled helium as a carrier gas at a linear velocity of $30 \mathrm{~cm}^{3} / \mathrm{s}$ (at 60 $\left.{ }^{\circ} \mathrm{C}\right)$. Injector and detector temperatures were maintained at $250{ }^{\circ} \mathrm{C}$ at $4{ }^{\circ} \mathrm{C} / \mathrm{min}$, respectively. The final temperature was held for 20 min. Peak areas and retention times were measured by electronic integration. The relative amounts of individual components were measured based on the peak areas obtained without FID response factor correction. Temperature programmed (linear) retention indices of the compounds were determined relative to n-alkanes.

GC-MS analysis were carried out on a Schimadzu GCMS-QP 5000 mass selective detector (MSD) directly coupled to a Schimadzu 17A gas chromatograph. A $25 \mathrm{~m}$ x $0.20 \mathrm{~mm}$ fused Silica HP-1 column, with a film thickness of $0.33 \mu$, was maintained up to $300{ }^{\circ} \mathrm{C}$ at $5{ }^{\circ} \mathrm{C} / \mathrm{min}$. The injector and GC/MS interface temperatures were maintained at $280^{\circ} \mathrm{C}$ and $300^{\circ} \mathrm{C}$, respectively. Pressure controlled Helium as carrier gas at a linear gas velocity of $44 \mathrm{~cm}^{3} / \mathrm{s}$ (at $60^{\circ} \mathrm{C}$ ) was used in this investigation. Electron ionization mass spectra were acquired over the mass range 10-400 Da at a rate 2/s.

The constituents of the oils were identified by matching their mass spectra 
and linear temperature programmed retention indices using NIST library search facility available with the instrument.

\section{Results and discussion}

The oil in the form of clear mobile liquid with characteristic smell of linalool obtained from the inflorescence and vegetative aerial parts of the species has shown its yield as $0.9 \%$ and $0.7 \%(\mathrm{v} / \mathrm{w}$ on FWB), respectively. GC and GC-MS analysis of the oils identified a total of 30 components for inflorescence and 17 components for vegetative aerial parts representing $96.9 \%-98.3 \%$ and $92.6 \%$ $92.8 \%$ of total oil respectively. The relative concentrations of the components identified are presented in Table 1 along with FID detection according to their elution order on the HP-1 column. Linalool was the major component found in the oils of both inflorescence $\quad(77.3 \%-80.2 \%) \quad$ and vegetative aerial parts (57.9\%-62.9\%). It is evident that there is a significant variation in the percentage composition of essential oils between the inflorescence and vegetative aerial parts with respect to major constituent. Trans-linalool oxide (furanoid) (8.4\%-9.9\%), cis-linalool oxide (furanoid) (8.3\%-9.3\%) and 3,7-dimethyl-1,5octadiene-3,7-diol (4.7\%-5.1\%) were found in higher amounts in the vegetative aerial parts than compared to inflorescence. In contrast, $\beta$-caryophyllene, caryophyllene oxide, $\rho$-cymene and borneol were found in higher amount in the inflorescence as compared to vegetative aerial parts.

The composition of the oil under investigation was quite different from the previously reported oils of the species which was collected from Jorhat (Assam) contained geranyl acetate (71\%) with linalool (5.27\%). In contrast, the present study has evidenced that linalool was the major component with minor amount of 1,8-cineol both in the oils of inflorescence and vegetative aerial parts (Table 1). Linalool (44.9\%) was also reported as major component in the oil of Elsholtzia blanda growing in the Himalayan Region of India (Thapp et al., 1999). However, the reported occurrence of linalool in the oil was maximum $44.9 \%$ only which was notably lesser then the oil (upto a maximum of $80.2 \%$ ) of the present investigation. The composition of essential oil of Elsholtzia blanda collected from India, rich in citral component was reported 75\%-83\% (Rana et al., 2012). However, geranial, neral, geranyl acetate and citral were not detected in the oil of the present investigation. Fang et al. (1990) reported 1,8-cineole (27.58\%) as the major component but our investigation have shown 1,8-cineole in very less amount both inflorescence and vegetative aerial parts. The present study have also attributed that the composition of essential oil of Elsholtzia blanda linalool as the major component in inflorescence (77.3\%-80.2\%) and in vegetative aerial parts $(57.9 \%$ $62.9 \%$ which is much higher in comparison to earlier report (44.9\%) (Thappa et al., 1999). The present findings thus clearly indicated that different composition of essential oil of Elsholtzia blanda from the two states of Northeast India, Assam (Jorhat) and Meghalaya (Foothill Areas of Nokrek Biosphere Reserve). The variation of chemical composition of these oils may be attributed to associated soil type and agroclimatic variation in their environmental conditions which might have played a key role in defining the chemical composition of the essential oils. However, the present findings has clearly indicated the existence of a linalool rich chemotype Elsholtzia blanda grows in the North-East India and can be used as a source of linalool. 
Table 1. Percentage compositions of the essential oils of inflorescence and vegetative aerial parts of Elsholtzia blanda (Benth.) Benth. collected from Meghalaya.

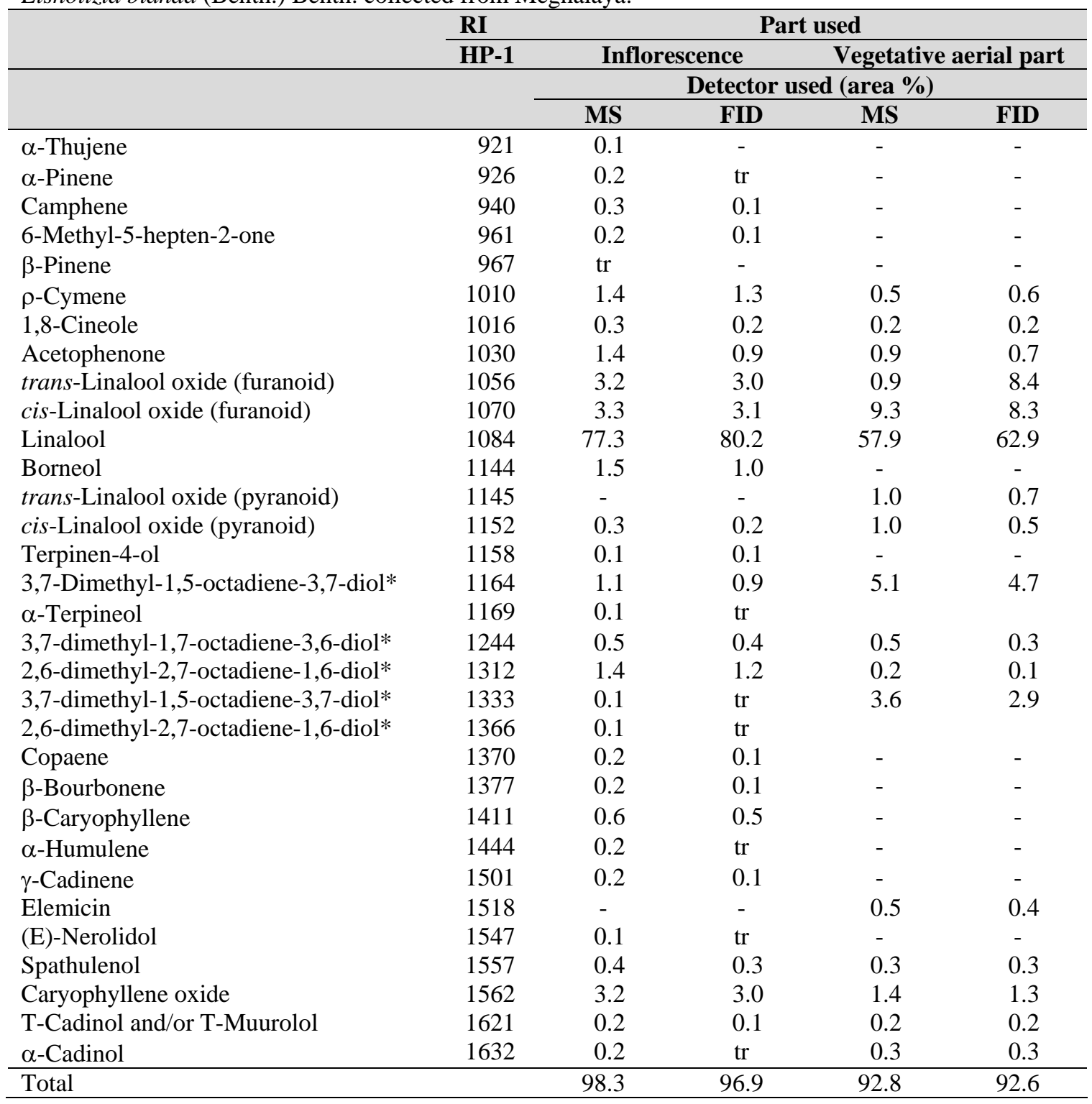

*correct isomeric form not identified; tr, trace $(<0.1)$.

Linalool has got great economic potentiallity in perfumes, hygienic product and in cleaning agent including soaps, detergents, shampoos and lotions. Moreover, is also used as chemical intermediate commonly as downstream product for Vitamin E. However, due to high economics involved in generation of naturally occurring linalool and its great demand for flavor and fragrance, synthetic and semi-synthetic products have been developed and around $6 \times 10^{6} \mathrm{~kg}$ of industrial linalool costing $\$ 10.0 / \mathrm{kg}$ are produced every year (Clark, 1988). Thus, the possibility in terms of exploration and potentiality towards commercial utilization of Elsholtzia blanda as an alternative ecofriendly natural source of linalool rich essential oil warrants in that depth detail study. 


\section{Conclusion}

The essential oil content in the inflorescence part of the Elsholtzia blanda Benth. of Meghalaya, North East India was reported for the first time. A comparative attempt has been made to observe that linalool was the major component in oils both inflorescence and vegetative aerial parts Elsholtzia blanda Benth. which is much higher to earlier report. The study has clearly demonstrated that the plant Elsholtzia blanda Benth. of Meghalaya with high linalool based essential oil can be a source of natural oil contents of high economic significance.

\section{Acknowledgments}

The authors are grateful to Dr. D. Ramaiah, Director CSIR-NEIST, Jorhat, for his keen interest in the work. The Council of Scientific \& Industrial Research (CSIR), New Delhi, is also acknowledged gratefully for providing financial support.

\section{Conflict of interest statement}

Authors declare that they have no conflict of interests.

\section{References}

Bestman, H. J.; Rauscher, J.; Vostrowsky, O.; Pant, A. K.; Dev, V.; Parihar, R.; Mathela, C. S. Constituent of the essential oil of Elsholtzia blanda Benth. (Labiatae). Journal of Essential Oil Research, v. 4, p. 121-124, 1992.

Cheng, B.; Xinxiang, M.; Xuejian, Yu.; Jingkai, D. A preliminary analysis of the acclimatization and essential oil components of Elsholtzia blanda. Acta Metallurgica Sinica, v. 11, No. 1, p. 1-3, 1989.

Clark, G. S. A profile: an aroma chemical Linalool. Perfumer Flav., v. 13, No. 8/9, p. 49-54, 1988.

Devi, A. D.; Devi, O. I.; Singh, T. C.; Singh, E. J. A study of aromatic plant species especially in Thoubal District, Manipur, NorthEast India. International Journal of Scientific and Research Publications, v. 4, n. 6 , p. 1-12, 2014.

Fang, H. J.; Xu, Y. O.; Lin, J. T. Studies on the chemical components of essential oil of Elsholtzia blanda Benth. Proceedings of the 11th International Congress of Essential Oils, Fragrances and Flavours, New Delhi, India, November, 1990. (v. 4, Chemistry Analysis and Structure). p. 49-53.

Lazaro, M. L. Distribution and biological activities of the flavonoid luteolin. Mid Review in Medicinal Chemistry, v. 9, p. 31-59, 2009.

Lesueur, D.; Bighelli, A.; Thitam, N.; Viet Than, N.; Thi Kim Dung, P.; Casanova, J. Composition and chemical variability of the essential oils of three Elsholtzia species from Vietnam: Elsholtzia blanda, Elsholtzia penduliflora and Elsholtzia winitiana. Natural Product Commun, v. 2, p. 857-861, 2007.

Lu, J. S.; Chen. T.; Guo, Z. The Chemical constituents of Elsholtzia blanda. Acta Bot. Sin., v. 43, p. 515-550, 2001.

Lv, J. S.; Shen, T.; Guo, Z.; Shen, X. W.; Zheng, S. Z. Chemical constituent of Elsoltzia blanda. Acta Bot. Sin., v. 43, p. 45-550, 2001.

Nath, S. C. Plant folk-medicines \& Medicinal Plants of North-East India. Jorhat, Assam: CSIR - North East Institute of Science and Technology, 2011.

Rana, V. S.; Devi, R. L.; Verdeguer, M.; Blazquez, M. A. Elsholtzia blanda Bennth: new citral-rich chemotypes from India. Journal of Herbs Spices \& Medicinal Plants, v. 18, No. 2, p. 132-139, 2012.

Singh, H. B.; Singh, R. S.; Sandhu, J. S. Herbal medicine of Manipur. Delhi: Daya Publishing House, 2003.

Singh, T. T.; Sharma, H. M.; Devi, A. R.; Rajanikanta, H. Plant used in the treatment of piles by the scheduled caste community of Andro Village in Imphal East District, Manipur (India). Journal of Plant Sciences, v. 2, No. 3, p. 113-119, 2014.

Thapp, R. K.; Agarwal, S. G.; Kapahi, B. K.; Srivastava, T. N. Chemodystematics of Himalayan Elsholtzia. J. Essential Oil Research, v. 11, p. 97-103, 1999.

Yonzong, G. S.; Yonzong, A.; Bhujel, R. B. Contribution to the ethnobotany of Darjeeling District, India. In: Jain, S. K. (Ed.). Ethnobotany and human welfare. New Delhi: Deep Publications, 1996. p. 388-389.

License information: This is an open-access article distributed under the terms of the Creative Commons Attribution License, which permits unrestricted use, distribution, and reproduction in any medium, provided the original work is properly cited. 